\title{
Micrométodo para quantificação de cefuroxima em plasma através da cromatografia líquida de alta eficiência. Aplicação na profilaxia de pacientes submetidos à cirurgia cardíaca
}

\author{
Jorge Willian Leandro Nascimento', Célia Etsuco Omosako², Maria José Carmona ${ }^{3}$, \\ José Otávio Auler Junior ${ }^{3}$, Silvia Regina Cavani Jorge Santos ${ }^{1 *}$
}

'Laboratório de Farmacologia e Terapêutica, Unidade de Pesquisa Clínica, Departamento de Farmácia, Faculdade de Ciências Farmacêuticas, Universidade de São Paulo, '2Laboratório de Farmacologia, Instituto do Coração Hospital das Clínicas, Faculdade de Medicina, Universidade de São Paulo, ${ }^{3}$ Serviço de Anestesiologia, Instituto do Coração Hospital das Clínicas, Faculdade de Medicina, Universidade de São Paulo

*Correspondência:

S. R. C. J. Santos

Departamento de Farmácia FCF-USP

Av. Prof. Lineu Prestes, 580

05389-970 - São Paulo - SP - Brasil

E-mail: parther@usp.br
O objetivo desta investigação foi desenvolver metodologia analítica adequada, simples e precisa para quantificação da cefuroxima plasmática para controle de pacientes cirúrgicos em profilaxia com esse antimicrobiano. Realizou-se a quantificação da cefuroxima na matriz biológica através da cromatografia líquida de alta eficiência CLAE-UV. Apenas $200 \mu \mathrm{L}$ de plasma foram requeridos para a precipitação das proteinas com acetonitrila. Empregou-se coluna de fase reversa (NovaPak C18, $150 \times 3,9 \mathrm{~mm}, 4 \mu \mathrm{m}$ ) e os picos foram eluidos isocraticamente com fase móvel (tampão acetato 0,375 M, pH 5,0 e acetonitrila, 96:4, v/v, 0,8 $\mathrm{mL} / \mathrm{min}$ ) em 12,5 min (cefuroxima) e 4,0 min (vancomicina, padrão interno) sendo os picos monitorados a $280 \mathrm{~nm}$. Os limites de confiança são referidos a seguir: 0,2-100 $\mu \mathrm{g} / \mathrm{mL}$ (linearidade, $r^{2}$ 0,9963), 0,1 $\mu \mathrm{g} / \mathrm{mL}$ (sensibilidade: $L D$ ), 98,2\% e 96,9\% (exatidão intra- e interdias), 3,2\% e 4,2\% (precisão intra- e inter-dias), e boa estabilidade e recuperação $(99,2 \%)$. A metodologia analítica foi aplicada para quantificação de cefuroxima no plasma de pacientes em profilaxia no periodo transoperatório de cirurgia cardíaca. Administraramse $6 \mathrm{~g}$ i.v. bolus de cefuroxima nas 24 horas, divididas em 4 doses de 1,5 g; após a última dose no início do pós-operatório tardio, as concentrações plasmáticas médias foram de 108,0 $\mu \mathrm{g} / \mathrm{mL}$ (zero), 32,8 $\mu \mathrm{g} / \mathrm{mL}$ ( $3^{a}$ hora), 9,9 $\mu \mathrm{g} / \mathrm{mL}$ (6 ${ }^{a}$ hora), 3,4 $\mu \mathrm{g} / \mathrm{mL}$ ( $9^{a}$ hora) e $0,8 \mu \mathrm{g} / \mathrm{mL}$ (12a hora). O método analítico descrito mostrou-se simples, rápido e seguro garantindo sensibilidade e seletividade suficientes para a quantificação da cefuroxima plasmática e monitoramento da antibioticoprofilaxia no paciente cirúrgico.

\author{
Unitermos: \\ - Cefuroxima \\ - CLAE-UV \\ - Profilaxia \\ - Cirurgia cardíaca
}

\section{INTRODUÇÃO}

O risco de infecção no período pós-operatório é reduzido pelo uso profilático de antibióticos, sendo a esco- lha do antimicrobiano baseada no tempo de recuperação do paciente (Kriaras et al., 1997; Vuorisalo et al., 1998).

Em concentrações terapêuticas, a cefuroxima é ativa contra Haemophilus influenzae, Moraxella catarrhalis, 
Streptococcus pneumoniae, Streptococcus pyogenes e outros estreptococos, excetuando-se o grupo D. A sensibilidade bacteriana à cefuroxima inclui ainda enterobactérias (Escherichia coli, Klebsiella pneumoniae, Proteus mirabilis, Salmonela sp e Shigela sp) e Staphylococcus aureus (cepas meticilina-sensíveis) e Staphylococcus epidermidis (Dellamonica, 1994). A concentração inibitória mínima (CIM90) deste antimicrobiano varia na faixa de 1-4 mg/mL para a maioria das bactérias sensíveis. Entretanto, dependendo da espécie e da cepa bacteriana, no caso da antibioticoprofilaxia e no tratamento das infecções do trato urinário, ortopedia e traumatologia ou na cirurgia geral, podem ser necessárias concentrações superiores do antimicrobiano circulante (Bundtzen et al., 1981; Kaukonen et al., 1995).

Na revascularização do miocárdio com circulação extracorpórea e hipotermia, CEC-H, a freqüência de infecções por $S$. aureus varia entre 12 e 36,4\% (Jacob et al., 2000). Este tipo de complicação é comum em cirurgias cardíacas com CEC-H e está associado a aumento da morbidade e da mortalidade dos pacientes, podendo chegar a 14\% das causas do óbito pós-cirúrgico (Trick et al., 2000; El Oakley et al., 1998).

Inúmeros métodos analíticos foram reportados utilizando as técnicas de cromatografia líquida de alta eficiência e a microbiológica para a quantificação de cefuroxima plasmática (Nilsson-Ehle, Nilsson-Ehle, 1978; Aziz et al., 1978; Bundtzen et al., 1981; Brisson, Fourtellan, 1981; Kaukonen et al., 1995). A cromatografia líquida de alta eficiência tem sido a escolhida pela seletividade, precisão e linearidade na faixa de trabalho requerida. De forma geral, a quantidade de amostra exigida na realização do ensaio laboratorial, o custo, o tempo para a emissão do laudo e a seletividade são fatores fundamentais e determinantes na escolha do método mais adequado. Desta forma, o objetivo do presente estudo foi desenvolver método analítico simples, sensível e seguro para a quantificação da cefuroxima plasmática por CLAE-UV, permitindo o monitoramento do paciente cirúrgico em profilaxia com este antimicrobiano.

\section{MATERIAL E MÉTODOS}

\section{Procedimento analítico}

Determinaram-se os níveis plasmáticos da cefuroxima através da cromatografia líquida de alta eficiência em fase reversa utilizando o detector universal ultravioleta. Efetuou-se a purificação da cefuroxima na matriz biológica (tubo Eppendorf, $2 \mathrm{~mL}$ ) pela precipitação das proteínas plasmáticas, adicionando-se $400 \mu \mathrm{L}$ de acetonitrila a $200 \mu \mathrm{L}$ de plasma contendo padrão interno (vancomicina 2,5 $\mu \mathrm{g} /$ ensaio). Procedeu-se à homogeneização em agitador de tubos horizontal, seguida de centrifugação, $10000 \mathrm{~g}$ por 30 minutos. Volumes de $200 \mu \mathrm{L}$ do sobrenadante foram transferidos para tubos cônicos de vidro para evaporação completa do solvente, sob corrente de nitrogênio, $37^{\circ} \mathrm{C}$. O resíduo foi dissolvido com $50 \mu \mathrm{L}$ da fase móvel, transferido para microvials e volume de $10 \mu \mathrm{L}$ submetido à análise cromatográfica através da injeção automática.

Utilizou-se cromatógrafo líquido SHIMADZU, sistema modulado constituído por bomba LC-10 AVP, injetor automático de amostras SIL-10ADVP e detector UV SPD-10A. A análise quantitativa da cefuroxima plasmática foi realizada em sistema cromatográfico constituído por coluna NovaPak ${ }^{\circledR} \mathrm{C} 18(150 \times 3,9 \mathrm{~mm}, 4 \mu \mathrm{m})$ e fase

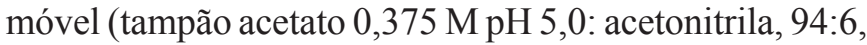
$\mathrm{v} / \mathrm{v}$ ) em fluxo de $0,8 \mathrm{~mL} / \mathrm{min}$.

Os picos referentes aos compostos eluídos foram monitorados em $280 \mathrm{~nm}$, registrados e a área, integrada por meio de registrador-integrador CR6A SHIMADZU.

A calibração foi obtida a partir da adição de solução padrão estoque $1 \mathrm{mg} / \mathrm{mL}$ a alíquotas de plasma humano livres do fármaco (branco de plasma) para fornecer as concentrações na faixa $0-200 \mu \mathrm{g} / \mathrm{mL}$. Construíram-se as curvas de calibração com base nos dados de concentração plasmática da cefuroxima e a razão da área (fármaco:padrão interno). A linearidade do método foi determinada pela análise de série de padrões, avaliando-se a concentração compreendida entre 0,2 e $200 \mu \mathrm{g} / \mathrm{mL}$ ( 11 calibradores, $\mathrm{n}=$ 3 replicatas). Os limites de detecção (LD) e quantificação (LQ) foram determinados a partir da análise de padrões em replicata ( $\mathrm{n}=5$ para cada limite), considerando-se a razão de sinal 3:1 e 10:1 relativamente ao ruído da linha de base para o LD e LQ, respectivamente.

Para os estudos de recuperação, precisão, exatidão, robustez e estabilidade utilizaram-se 3 concentrações: alta (200 $\mu \mathrm{g} / \mathrm{mL})$, média $(12,5 \mu \mathrm{g} / \mathrm{mL})$ e baixa $(0,8 \mu \mathrm{g} / \mathrm{mL})$.

Determinaram-se as recuperações relativa e absoluta pelo ensaio de replicatas, $n=10$, para os padrões nas 3 concentrações distintas. A inexatidão ou erro sistemático foi determinada pela análise de replicatas $\mathrm{n}=10$ de forma semelhante, sendo expressa em \%. Determinou-se a precisão pela análise quantitativa de replicatas $\mathrm{n}=5 \mathrm{em} 1$ dia para a precisão intra-dia e em 3 dias para a precisão inter-dias, sendo expressas através do coeficiente de variação ( $\mathrm{CV} \%)$.

Efetuaram-se ligeiras modificações no sistema cromatográfico, de forma a testar a robustez do método, conforme referidas a seguir: 1) Modificação na fase móvel: tampão acetato $0,375 \mathrm{M} \mathrm{pH} \mathrm{5,0:} \mathrm{acetonitrila,} \mathrm{95:5} \mathrm{(v/v)}$ em substituição à definida anteriormente; 2) Modificação no fluxo da fase móvel: fluxo $(0,7 \mathrm{~mL} / \mathrm{min})$ ao invés 
de $0,8 \mathrm{~mL} / \mathrm{min}$; 3) Utilização de outra coluna analítica de fase reversa: outro lote de NovaPak C18, 150 x 3,9 mm, $4 \mathrm{~mm}$.

Paralelamente à calibração do dia, prepararam-se controles de qualidade internos para a garantia dos resultados obtidos em cada série de análises efetuadas. Amostras de plasma foram adicionadas de cefuroxima nas concentrações de $0,8 \mu \mathrm{g} / \mathrm{mL}$ (baixo); $50 \mu \mathrm{g} / \mathrm{mL}$ (médio); e $200 \mu \mathrm{g} / \mathrm{mL}$ (alto). Para cada lote analisado de amostras dos pacientes, estes controles foram injetados, de forma intercalada com as amostras.

Investigou-se a estabilidade da cefuroxima na matriz biológica ou extratos orgânicos através da avaliação: a) estabilidade do fármaco no extrato seco até 3 horas a temperatura ambiente, previamente à corrida cromatográfica $(n=6) ; b)$ estabilidade do fármaco após 3 ciclos de congelamento e descongelamento $(n=9)$; c) estabilidade de longa duração até 3 meses em congelador, $20{ }^{\circ} \mathrm{C}$ negativos $(n=6)$; $)$ estabilidade da cefuroxima na bandeja (injetor automático) durante corrida analítica do dia $(\mathrm{n}=6)$. Os resultados dos testes de estabilidade foram expressos através da perda percentual, referente à concentração obtida relativamente ao valor nominal.

\section{Casuística e Protocolo Clínico}

Preconiza-se a antibioticoprofilaxia no paciente cirúrgico utilizando-se o total de $6 \mathrm{~g}$ divididas em quatro doses de 1,5 g i.v. de cefuroxima, no transoperatório de revascularização do miocárdio com CEC, conforme detalhado a seguir. Investigaram-se cinco pacientes coronarianos adultos, de ambos os sexos $(3 \mathrm{M}$ e $2 \mathrm{~F}, 48$ anos, $72,4 \mathrm{~kg}, 1,66 \mathrm{~m}, 26,2 \mathrm{~m}^{2}$, valores médios), com indicação cirúrgica para revascularização do miocárdio com CEC$\mathrm{H}$. Administraram-se $6 \mathrm{~g}$ de cefuroxima em 24 horas $(4 \mathrm{x}$ $1,5 \mathrm{~g}$ i.v. bolus) através de injeção intravenosa: a $1^{\text {a }}$ dose foi efetuada no momento da indução anestésica e previamente a incisão; a $2^{\text {a }}$ dose ao término da CEC-H; a $3^{\text {a }}$ dose no pós-operatório imediato e a $4^{\text {a }}$ dose (última dose) no início do pós-operatório tardio, isto é na $24^{\mathrm{a}}$ hora da indução na sala de operação. Efetuou-se coleta seriada de amostras sangüíneas (3 a $5 \mathrm{~mL}$ ) após administração da última dose da medicação nos períodos zero (ao término da administração), 3, 6, 9 e 12 horas da injeção em bolus. Uma vez que o paciente se encontra anticoagulado com heparina, de forma a se evitar os riscos de tromboembolia e re-infarto, as coletas foram efetuadas em tubo seco contendo gel. As amostras de sangue foram centrifugadas a $3000 \mathrm{~g}$ durante 20 minutos, o plasma separado e armazenado em congelador $\left(20^{\circ} \mathrm{C}\right.$, negativos) até o momento da análise. A quantificação da cefuroxima nas amostras dos pacientes foi realizada pela aplicação do método analítico acima detalhado. Todos os pacientes foram informados em detalhes sobre o protocolo de estudo e coleta seriada de amostras sangüíneas, fornecendo o consentimento escrito pósinformação. O protocolo foi submetido e aprovado pelos Comitês de Ética das Instituições envolvidas.

\section{RESULTADOS E DISCUSSÃO}

O método analítico descrito no presente estudo foi validado com base nos parâmetros dos limites de confiança para a quantificação da cefuroxima plasmática. A cefuroxima e seu padrão interno foram eluídos da coluna cromatográfica em 12,5 min e 4,8 min, respectivamente (Figura 1), sendo o tempo de corrida exigido para cada análise equivalente a 15 minutos, permitindo a realização de grande número de ensaios diariamente. Este método analítico apresentou alta sensibilidade, $0,1 \mu \mathrm{g} / \mathrm{mL}$ (LD) e $0,2 \mu \mathrm{g} / \mathrm{mL}$ (LQ), linearidade entre $0,2-200 \mu \mathrm{g} / \mathrm{mL}$, recuperação, exatidão e precisão aceitáveis (Tabela I). A curva de calibração para a cefuroxima em plasma foi construída a partir de 11 concentrações, conforme ilustrada na Figura 2.

TABELA I - Limites de confiança do método analítico para quantificação da cefuroxima plasmática

\begin{tabular}{lc}
\hline Parâmetro & Valores Obtidos \\
\hline Linearidade & $0,2-200 \mu \mathrm{g} / \mathrm{mL}$ \\
Regressão linear & $\mathrm{r}^{2}=0,9963$ \\
Limite de detecção & $0,1 \mu \mathrm{g} / \mathrm{mL}$ \\
Limite de quantificação & $0,2 \mu \mathrm{g} / \mathrm{mL}$ \\
Estabilidade & \\
Ciclo de congelamento $(*)$ & $94,9-98,4 \%$ \\
Após 3 meses $\left(^{*}\right)$ & $96,2-100 \%$ \\
Extrato seco $\left(^{*}\right)$ & $84,5-88,2 \%$ \\
Na bandeja $\left(^{*}\right)$ & $94,4-96,2 \%$ \\
Precisão $(\mathrm{CV})$ & \\
Intra-dia $(*)$ & $3,2 \%$ \\
Inter-dias $(*)$ & $4,2 \%$ \\
Exatidão & \\
Intra-dia $(*)$ & $98,2 \%$ \\
Inter-dias $(*)$ & $96,9 \%$ \\
Recuperação $(*)$ & $99,2 \%$ \\
Robustez & \\
Fase móvel $(*)$ & $-3,2 \%$ \\
Fluxo $(*)$ & $-5,7 \%$ \\
Coluna $(*)$ & $-5,4 \%$ \\
\hline
\end{tabular}

(*) Valores expressos através da média referente às 3 concentrações avaliadas para cada teste: alta $(200 \mu \mathrm{g} / \mathrm{mL})$, média $(12,5 \mu \mathrm{g} / \mathrm{mL})$ e baixa $(0,8 \mu \mathrm{g} / \mathrm{mL})$ 


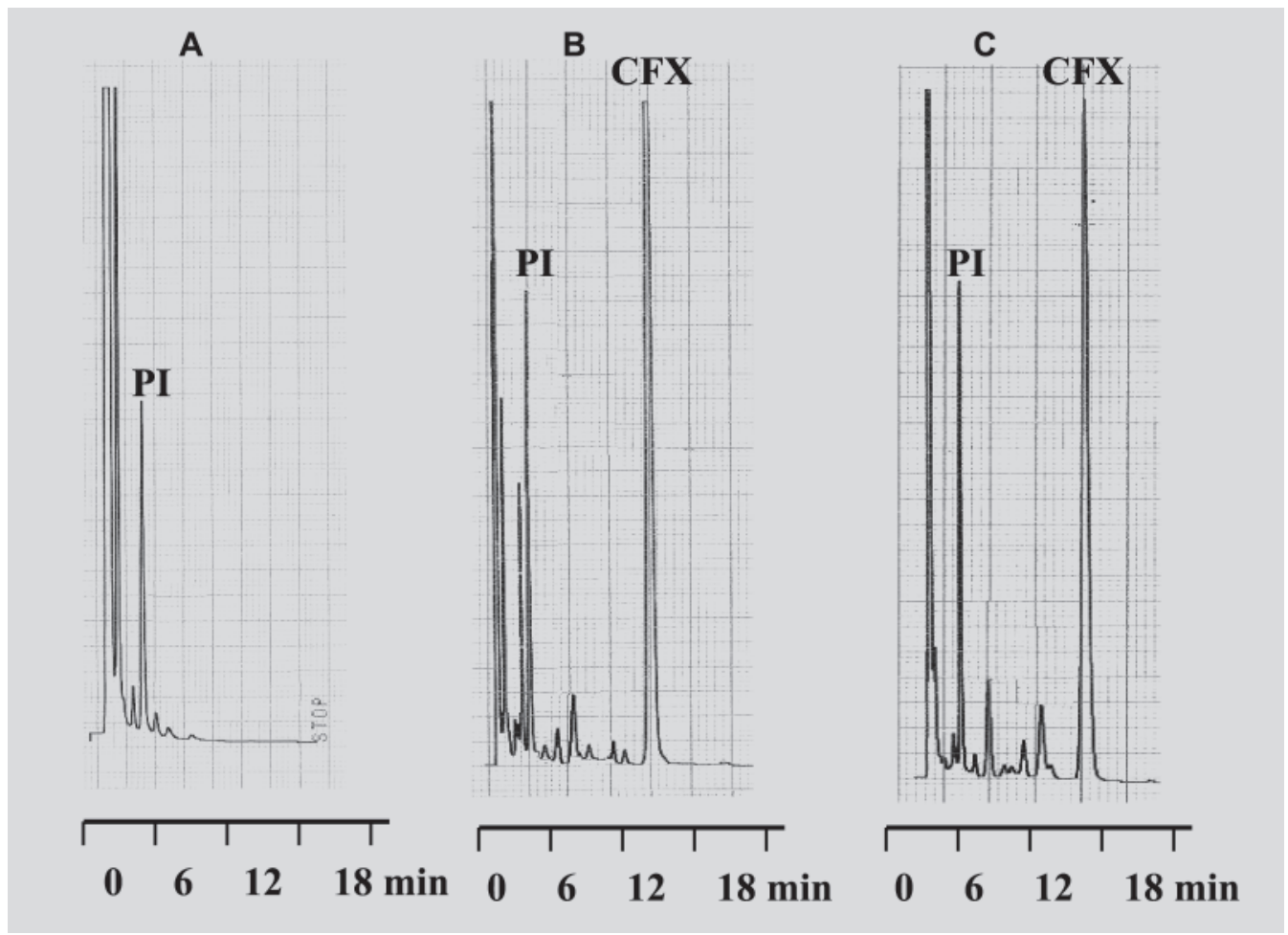

FIGURA 1 - Perfil cromatográfico CLAE UV da cefuroxima plasmática. (A) Branco de plasma com padrão interno; (B) Padrão de plasma contendo $50 \mu \mathrm{g} / \mathrm{mL}$; (C) amostra de paciente no transoperatório de revascularização do miocárdio. Tempos de retenção: 4,0 min (padrão interno) e 12,5 min (cefuroxima).

\section{Linearidade Cefuroxima}

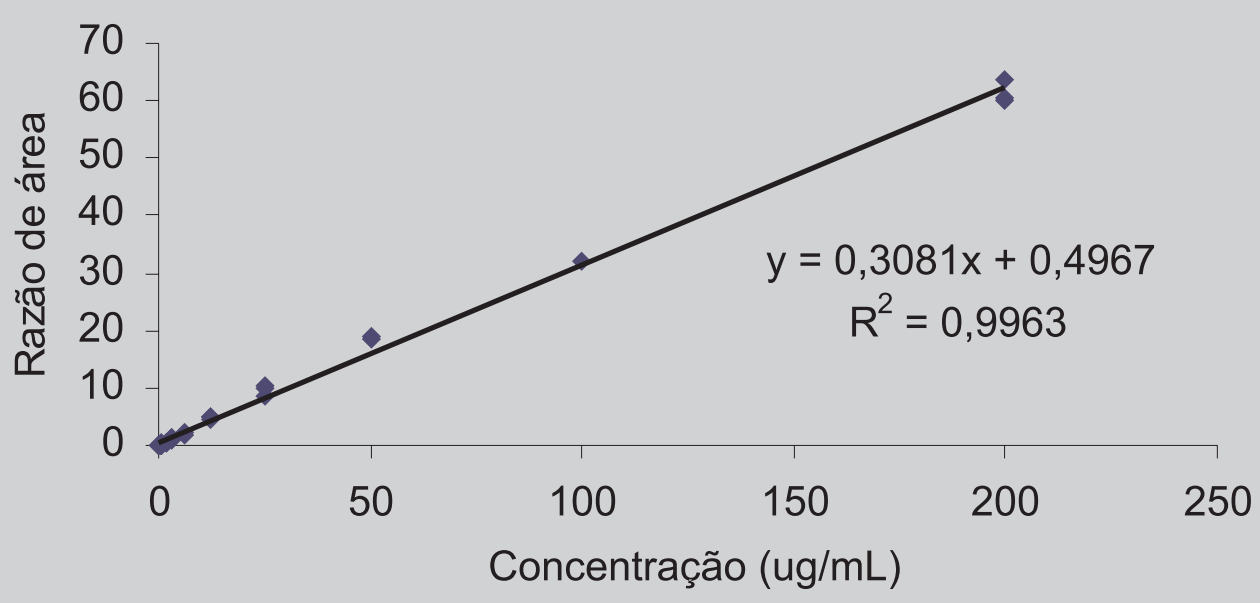

FIGURA 2 - Curva de calibração para a cefuroxima na faixa de 0,2 a $200 \mu \mathrm{g} / \mathrm{mL}$, utilizada para avaliação da linearidade, 11 calibradores $(n=3)$. 
A literatura é escassa nos procedimentos analíticos para a quantificação da cefuroxima em matrizes biológicas envolvendo técnicas cromatográficas e não cromatográficas (Nilsson-Ehle, Nilsson-Ehle, 1978; Aziz et al., 1978; Brisson, Fourtellan, 1981; Bundtzen et al., 1981; Kaukonen et al., 1995), uma vez que a eletroforese capilar (Sciacchitano et al., 1994) e a CLAE vêm sendo aplicadas na determinação de inúmeras cefalosporinas em produtos farmacêuticos (Su et al., 1984; Das Gupta, 1984; Fabre et al., 1984; Lorenz et al., 1992).

A utilização da técnica microbiológica reportada para determinação de cefuroxima em plasma apresentou como desvantagem a baixa seletividade e estreita linearidade frente à técnica de CLAE-UV (Bundtzen et al., 1981). Reportaram-se, ainda, dois outros métodos utilizando a técnica de CLAE-UV para a determinação da cefuroxima plasmática, empregando a extração líquidolíquido na purificação da matriz biológica (Nilsson-Ehle, Nilsson-Ehle, 1978; Brisson, Fourtellan, 1981). Nesses procedimentos exigiu-se o tratamento do plasma com dimetilformamida previamente à CLAE-UV, (NilssonEhle, Nilsson-Ehle, 1978) ou à extração líquido-líquido do plasma com mistura de clorofórmio:pentanol 3:1, v/v, seguida de re-extração da fase orgânica com tampão fosfato 0,01 M, pH 7,0 (Brisson, Fourtellan, 1981). De forma geral, estes métodos mostraram-se trabalhosos para a garantia da seletividade do método cromatográfico.

Outros procedimentos de purificação da matriz biológica empregam, no preparo da amostra, a adição de agentes precipitantes das proteínas em substituição à extração líquido-líquido (Aziz et al., 1978; Bundtzen et al., 1981; Holt et al., 1990; Kaukonen et al., 1995). Previamente à análise cromatográfica, Aziz et al. (1978) reportaram a precipitação de proteínas plasmáticas pela adição de mistura de tampão acetato $0,2 \mathrm{M} \mathrm{pH} 5,2$ e metanol $(40: 60, \mathrm{v} / \mathrm{v})$ à matriz biológica; este procedimento foi modificado posteriormente por Bundtzen et al. (1981) para quantificação de cefuroxima. $\mathrm{O}$ uso de outros agentes precipitantes de proteínas foi reportado por Holt et al. (1990) e Kaukonen et al. (1995), que empregaram o ácido perclórico 4\% com desvantagens relativas à vida média da coluna e $\mathrm{pH}$ do fluído injetado no sistema cromatográfico. A utilização da acetonitrila na proporção de 2 volumes para 1 de plasma, como precipitante de proteínas plasmáticas, se mostrou eficiente e pouco agressivo ao sistema cromatográfico, conforme descrito no presente estudo.

A escolha da coluna analítica e da fase móvel é crítica e fator determinante da seletividade cromatográfica. Nas décadas de 70-80, utilizaram-se colunas de fase reversa tipo m-bondapack $\mathrm{C} 18,10 \mu \mathrm{m}(300 \times 3,9 \mathrm{~mm}$, diâmetro interno), e fase móvel binária constituída por mistura de metanol e ácidos fracos, tampões ( $\mathrm{pH} 3,0$ - 7,0) em diversas proporções (Nilsson-Ehle, Nilsson-Ehle, 1978; Brisson, Fourtellan, 1981; Holt et al., 1990). Posteriormente, substituíram-se aquelas colunas por outras de maior eficiência, como a Spherisorb 5 ODS-2 (150 x 4,6 $\mathrm{mm}$ ), reportada por Kaukonen et al. (1995) e a NovaPak C18, $4 \mu \mathrm{m},(150 \times 3,9 \mathrm{~mm})$, empregada no presente estudo; a fase móvel em ambos os casos foi preparada com tampão fosfato ou acetato e acetonitrila, garantindo-se a seletividade do sistema cromatográfico, boa reprodutibilidade dos resultados e operação do sistema em menor fluxo, relativamente àquelas contendo metanol.

Com relação à sensibilidade da metodologia, os fatores determinantes estão vinculados fundamentalmente à técnica analítica empregada e ao volume de amostra requerido no ensaio. Alguns procedimentos analíticos reportados anteriormente evidenciaram boa sensibilidade (Nilsson-Ehle, Nilsson-Ehle, 1978; Brisson, Fourtellan, 1981), entretanto, volume relativamente grande da matriz biológica foi requerido. Posteriormente, outros procedimentos foram publicados utilizando apenas $0,1-0,2 \mathrm{~mL}$ de plasma (Bundtzen et al., 1981; Holt et al., 1990; Kaukonen et al., 1995). Da mesma forma, o micrométodo descrito no presente estudo utilizou volume reduzido da matriz biológica e precipitação de proteínas plasmáticas, mostrando-se seletivo para a análise de cefuroxima, uma vez que não se registraram picos interferentes durante a corrida analítica (Figura 1). A aplicação do método analítico desenvolvido para a quantificação de cefuroxima plasmática nos pacientes cirúrgicos em antibioticoprofilaxia é ilustrada na Figura 3.

Reportou-se anteriormente que a administração intravascular de $750 \mathrm{mg}$ para a cefuroxima mantém níveis plasmáticos acima de de $2 \mu \mathrm{g} / \mathrm{mL}$ apenas nas primeiras horas da injeção. Adicionalmente, doses de 1,5 g mantêm níveis circulantes bactericidas no paciente cirúrgico até 4 horas da administração, em decorrência da alta depuração plasmática desse antimicrobiano hidrofílico. A curta meia-vida pode estar prolongada pela co-administração de probenecida, conhecido inibidor da secreção tubular renal (Garton et al., 1997). Como a taxa de ligação do fármaco às proteínas plasmáticas é baixa e o volume de distribuição é pequeno $(0,200 \mathrm{~L} / \mathrm{kg})$, tem-se recomendado dose suplementar do antimicrobiano para pacientes submetidos à diálise (Emmerson et al., 1988). Adicionalmente, uma vez que a eliminação do fármaco é dependente da função renal, o intervalo entre doses deve ser aumentado para os pacientes portadores de insuficiência renal grave e uremia (Bundtzen et al., 1981).

Se a concentração inibitória mínima (CIM90) deste antimicrobiano no steady state é da ordem de $4 \mu \mathrm{g} / \mathrm{mL}$ 
para a maioria das bactérias, esquemas de dose de 1,5 g, 2 a 4 vezes ao dia têm sido recomendados, durante período de até 48 horas, para a profilaxia das infeções nos pacientes submetidos a cirurgia pulmonar e cardíaca com CEC (Bernard et al., 1994; Wellens et al., 1995; Jakob et al., 2000; Trick et al., 2000): uma série de fatores deve, ainda, ser considerada no pré- e no intra-operatório, tais como escolha do agente antimicrobiano, presença de obesidade e, para os pacientes portadores de diabetes mellitus, glicemia: acima de $200 \mathrm{mg} / \mathrm{dL}$ (Trick et al., 2000).

A administração de cefuroxima ou cefazolina, agentes de escolha propostos anteriormente na profilaxia das infecções em cirurgia cardíaca e geralmente administrados em doses de $3 \mathrm{~g}$ nas 24 horas (Wellens et al., 1995), foi contestada por Jakob et al. (2000), que sugeriram a administração de doses de 1,5 g, 3 vezes ao dia, totalizando 4,5 g diários para os pacientes cirúrgicos submetidos a CEC-H.

No presente estudo, ao paciente coronariano submetido a cirurgia cardíaca com CEC-H, em antibioticoprofilaxia das infecções cirúrgicas, administraram-se $6 \mathrm{~g}$ de cefuroxima (4 doses de 1,5 g em 24 horas). Após a administração da $4^{\mathrm{a}}$ e última dose, no início do pós-operatório tardio, efetuou-se a coleta seriada de sangue, fornecendo os resultados ilustrados na Figura 3.

Evidenciou-se que a cefuroxima administrada ao paciente coronariano, conferiu picos plasmáticos elevados variando entre 85-131 $\mu \mathrm{g} / \mathrm{mL}$, IC95, imediatamente após a injeção da cefuroxima, reduzindo-se rapidamente para concentrações, expressas pelas médias, desvio padrão (IC95\%): $32,8 \pm 3,8 \mu \mathrm{g} / \mathrm{mL}$ ( $3^{\mathrm{a}}$ hora, $\left.28-38 \mu \mathrm{g} / \mathrm{mL}\right), 9,9 \pm 3,3 \mu \mathrm{g} / \mathrm{mL}$
(6 hora, 5-14 $\mu \mathrm{g} / \mathrm{mL}$ ), 3,4 $\pm 1,6 \mu \mathrm{g} / \mathrm{mL}$ (9 hora, $1-6 \mu \mathrm{g} / \mathrm{mL}$ ) e $0,8 \pm 1,1 \mu \mathrm{g} / \mathrm{mL}$ (12 ${ }^{\mathrm{a}}$ hora, $0-2,4 \mu \mathrm{g} / \mathrm{mL}$ ), conforme ilustrado na Figura 3. Baixas concentrações plasmáticas foram registradas precocemente para a cefuroxima, já a partir da $6^{\text {a }}$ hora; tais resultados não eram esperados pelo esquema de dose utilizado que gerou níveis inferiores aos requeridos na antibioticoprofilaxia $(16 \mu \mathrm{g} / \mathrm{mL}: 4 \mathrm{x}$ $4 \mu \mathrm{g} / \mathrm{mL}$, MIC). Conseqüentemente, sugere-se que o esquema terapêutico deva ser reavaliado, para se atingir níveis circulantes adequados e manutenção dos mesmos no intervalo entre doses, de forma a garantir a antibioticoprofilaxia no paciente cirúrgico com a cefuroxima.

Com base nos resultados obtidos no presente estudo, conclui-se que a metodologia analítica proposta se mostrou seletiva e suficientemente sensível para a detecção de até $0,1 \mu \mathrm{g} / \mathrm{mL}$, possibilitando determinação dos níveis plasmáticos circulantes bastante baixos para a cefuroxima. Além disso, a linearidade obtida contempla as concentrações encontradas após administração de 1,5 g de cefuroxima i.v., sendo os limites de quantificação e de detecção considerados adequados para o monitoramento da antibioticoprofilaxia no paciente cirúrgico. O método analítico mostrou-se robusto e vantajoso relativamente àqueles reportados na literatura pela sensibilidade, seletividade, rapidez e simplicidade do procedimento, garantindo a realização de grande número de ensaios a custo reduzido. Complementarmente, a aplicação do método evidenciou baixas concentrações para a cefuroxima circulante no paciente cirúrgico $\left(1^{\circ} \mathrm{PO}\right)$, inferiores aos níveis profiláticos requeridos.

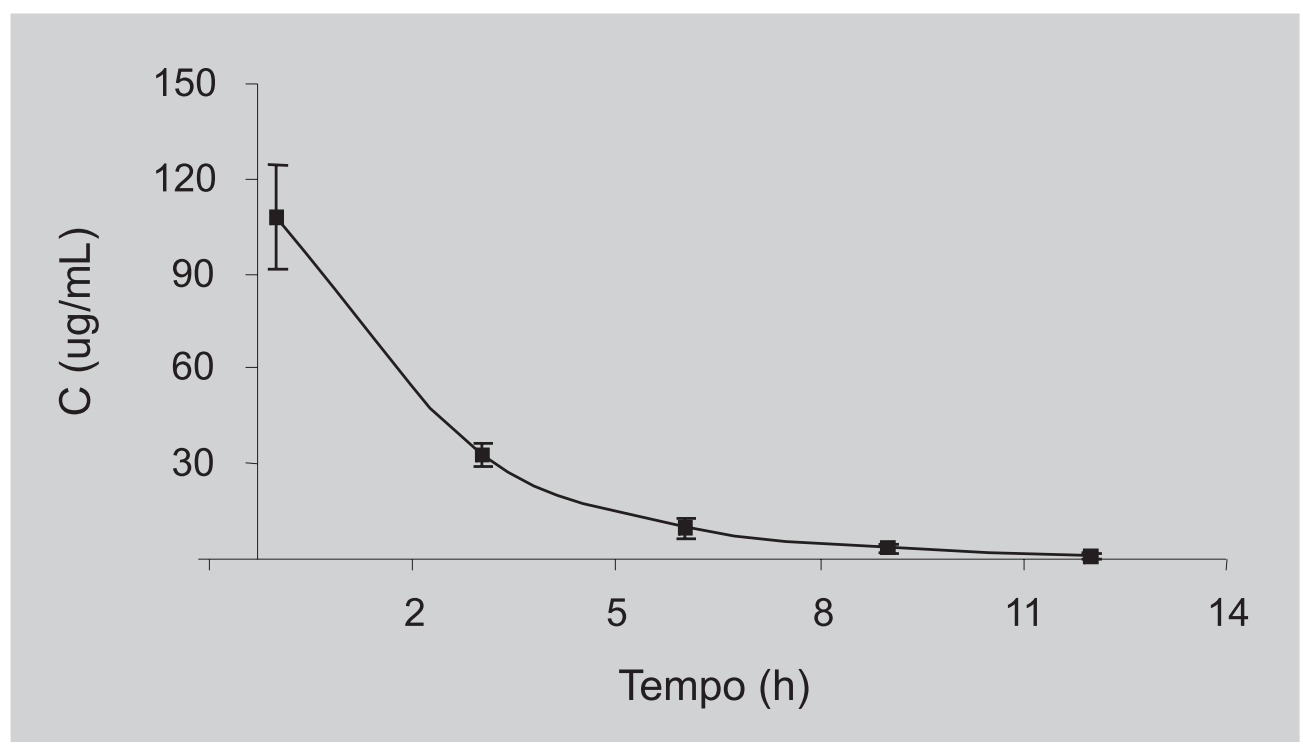

FIGURA 3 - Níveis plasmáticos de cefuroxima no pós-operatório de cirurgia cardíaca após administração da $4^{\mathrm{a}}$ dose ( $1^{\circ} \mathrm{PO}$ tardio), concentrações médias e desvios padrão, $\mathrm{n}=5$. 


\section{ABSTRACT}

Micromethod for plasma cefuroxime quantification through high performance liquid chromatography. Application to the prophylaxy of patients submitted to cardiac surgery

An improved, simple, selective and sensitive micromethod based on HPLC-UV is described to determine cefuroxime plasma levels, a second generation cephalosporin. Once changes on pharmacokinetics of drugs in patients submitted to heart surgery with cardiopulmonary bypass and hypothermia $(C P B-H)$ were reported previously, the objective of the present study was to investigate cefuroxime plasma levels for antimicrobial prophylaxis of infections in those patients after surgery using HPLC-UV. Only $200 \mu L$ of plasma were required, and cefuroxime was determined by a chromatographic method using reversed phase system, after a simple clean up of plasma samples. Peaks monitored at $280 \mathrm{~nm}$ were eluted isocratically at $12.5 \mathrm{~min}$ (cefuroxime) and at $4.0 \mathrm{~min}$ (vancomicyn, internal standard,) from a $4 \mu \mathrm{m}$, NovaPak column $(150 \times 3.9 \mathrm{~mm})$ using a binary mobile phase at flow rate $0.8 \mathrm{~mL} / \mathrm{min}$, consisting of $0.375 \mathrm{M}$ acetate buffer, $p H$ 5, 0 and acetonitrile, 96:4 (v/v). The method validated with basis of parameters evaluated for the confidence limits of cefuroxime measurements in spiked blank plasma, presents $0.1 \mu \mathrm{g} / \mathrm{mL}$ sensitivity, $0.2-200 \mu \mathrm{g} / \mathrm{mL}$ linearity, ( $\left.r^{2} 0.998\right)$, systematic error of 98.2\% and $96.9 \%$ (intra- and interday accuracy), intra- and interday precision (CV\%: $3.2 \%$ and $4.2 \%$ ). A good stability and high percentage of recovery (99.2\%) were obtained. Patients received cefuroxime $6 \mathrm{~g}$ i.v. bolus $(1,5 \mathrm{~g}$, 4 times in 24 hours), showed in the first postoperative day plasma levels of $108.0 \mu \mathrm{g} / \mathrm{mL}$ (zero), $32.8 \mu \mathrm{g} / \mathrm{mL}\left(3^{\text {rd }} \mathrm{h}\right.$ ), $9.9 \mu \mathrm{g} / \mathrm{mL}$ ( $6^{\text {th }} \mathrm{h}$ ), $3.4 \mu \mathrm{g} / \mathrm{mL}\left(9^{\text {th }} \mathrm{h}\right)$ and $0.8 \mu \mathrm{g} / \mathrm{mL}\left(12^{\text {th }} \mathrm{h}\right)$, after the last dose.

UNITERMS: Cefuroxime. Plasma. HPLC-UV. Prophylaxis. Heart surgery.

\section{AGRADECIMENTOS}

À FAPESP, pelo auxílio à pesquisa concedido para este projeto (processo 01/ 02613-2), e ao CNPq (processo 141518/2000-6), pela bolsa DT e a Valéria Adriana Pereira, doutoranda FBC-FCFUSP, pela colaboração na parte gráfica e revisão deste manuscrito.

\section{REFERÊNCIAS BIBLIOGRÁFICAS}

AZIZ, N. S.; GAMBERTOGLIO, J. G.; LIN, E. T.; GRAUSZ, H.; BENET, L. Z. Pharmacokinetics of cefamandole using a HPLC assay. J. Pharm. Biopharm., Shannon, v.6, n.2, p.153-164, 1978.

BERNARD, A.; PILLET, M.; GOUDET, P.; VIARD, H. Antibiotic prophylaxis in pulmonary surgery: a prospective randomized double-blind trial of flash cefuroxime versus forty-eight-hour cefuroxime. $J$. Thorac. Cardiovasc. Surg., Saint Louis, v.107, n.3, p.896-900, 1994.

BRISSON, A. M.; FOURTILLAN, J. B. Determination of cephalosporins in biological material by reversed-phase liquid column chromatography. J. Chromatogr., Amsterdam, v.223, p.393-399, 1981.

BUNDTZEN, R. W.; TOOTHAKER, R. D.; NIELSON, O. S.; MADSEN, P. O.; WELLING, P. G.; CRAIG, W. A. Pharmacokinetics of cefuroxime in normal and impaired renal function: comparison of high-pressure liquid chromatography and microbiological assays. Antimicrob. Agents Chemother., Washington, v.19, n.3, p.443-449, 1981.

DAS GUPTA, V. Stability of cefotaxime sodium as determined by high-performance liquid chromatography. J. Pharm. Sci., New York, v.73, n.4, p.565-567, 1984.

DELLAMONICA, P. Cefuroxime axetil. Int. J. Antimicrob. Agents, Amsterdam, v.4, n.1, p.23-36, 1994.

EL OAKLEY, R.; PAUL, E.; WONG, P. S. Mediastinitis in patients undergoing cardiopulmonary bypass: risk analysis and midterm results. J. Cardiovasc. Surg., Torino, v.38, p.595-600, 1998.

EMMERSON, A. M. Cefuroxime axetil. J. Antimicrob. Chemother., Oxford, v.22, n.2, p.101-104, 1988.

FABRE, H.; EDDINE, N. H.; BERGE, G. Degradation kinetics in aqueous solution of cefotaxime sodium, a third-generation cephalosporin. J. Pharm. Sci., New York, v.73, n.5, p.611-739, 1984. 
GARTON, A. M.; RENNIE, R. P.; GILPIN, J.; MARRELLI, M.; SHAFRAN, S. D. Comparison of dose doubling with probenecid for sustaining serum cefuroxime levels. $J$. Antimicrob. Chemother., Oxford, v.40, n.6, p.903-906, 1997.

HOLT, D. E.; LOUVOIS, J.; HURLEY, R.; HARVEY, D. A high performance liquid chromatography system for the simultaneous assay of some antibiotics commonly found in combination in clinical samples. J. Antimicrob. Chemother., Oxford, v.26, p.107-115, 1990.

JACOB, H. G.; BORNEFF-LIPP, M.; BACH, A.; PUCKLER, S.; WINDELER, J.; SONNTAG, H.; HAGL, S. The endogenous pathway is a major route for deep sternal wound infection. Eur. J. Cardio-Thorac. Surg., Heidelberg, v.17, p.154-160, 2000.

KAUKONEN, J. P.; TUOMAINEN, P.; MAKIJARVI, J.; MOKKA, R.; MANNISTO, P. T. Intravenous cefuroxime prophylaxis. Acta Orthop. Scand, Copenhagen, v.66, n.1, p.14-16, 1995.

KRIARAS, I.; MICHALOPOULOS, A.; MICHALIS, A.; PALATIANOS, G.; ECONOMOPOULOS, G.; ANAGNOSTOPOULOS, C.; GEROULANOS, S. Antibiotic prophylaxis in cardiac surgery. J. Cardiovasc. Surg., Torino, v.38, n.6, p.605-610, 1997.

LORENZ, L. J.; BASHORE, F. N.; OLSEN, B. A. Determination of process-related impurities and degradation products in cefaclor by high-performance liquid chromatography. J. Chromatogr. Sci., Niles, v.30, p.211-216, 1992.

NILSSON-EHLE, I.; NILSSON-EHLE, P. Liquid chromatographic assay of cefuroxime in serum. Clin. Chem., Washington, v.24, n.2, p.365-367, 1978.
PERRY, C. M.; BROGDEN, R. N. Cefuroxime axetil: a review of its antibacterial activity, pharmacokinetic properties and therapeutic efficacy. Drugs, Auckland, v.52, n.1, p.125-158, 1996.

SCIACCHITANO, C. J.; MOPPER, B.; SPECCHIO, J. Identification and separation of five cephalosporins by micellar eletrokinetic capillary chromatography. $J$. Chromatogr. B: Biomed. Sci. Appl., Amsterdam, v.657, n.2, p.395-399, 1994.

SU, K. S. E.; QUAY, J. F.; CAMPANALE, K. M.; STUCKY, J. F. Nonaqueous cephalosporin suspension for parenteral administration: cefazolin sodium. J. Pharm. Sci., New York, v.73, n.11, p.1602-1606, 1984.

TARTAGLIONE, T. A.; POLK, R. E. Review of the new second-generation cephalosporins: cefonicid, ceforanide, and cefuroxime. Drug Intell. Clin. Pharm., Hamilton, v.19, n.3, p.188-198, 1985.

TRICK, W. E.; SCHECKLER, W. E.; TOKARS, J. I.; JONES, K. C.; RAPPEN, M. L.; SMITH, E. M.; JARVIS, W. R. Modifiable risk factors associated with deep sternal site infection after coronary artery bypass grafting. J. Thorac. Cardiovasc. Surg., Saint Louis, v.119, p.108-114, 2000.

VUORISALO, S.; POKELA, R.; SYRJÄLÄ, H. Comparison of vancomycin and cefuroxime for infection prophylaxis in coronary artery bypass surgery. Infect. Control Hosp. Epidemiol., Thorofare, v.19, n.4, p.234239, 1998.

WELLENS, F.; PIRLET, M.; LARBUISSON, R.; DE MEIRELEIRE, F.; DE SOMER, P. Prophylaxis in cardiac surgery: a controlled randomized comparison between cefazolin and cefuroxime. Eur. J. CardioThorac. Surg., Heidelberg, v.9, n.6, p.325-329, 1995.

Recebido para publicação em 30 de agosto de 2002. 